\title{
The impact of fear in the post covid era
}

\begin{abstract}
Feeling fear is involuntary, as it is often unconscious. However, there are other faces of fear that we can recognize and that are familiar to us. We go from real fears to unreal fears, from present fears to projective fears that are reinforced and mutate into other more complex situations that further reinforce our fear. The more we reinforce these thoughts the stronger our fear becomes. So, what is feeding our fear? How do we react to fear? Is it the desire to dodge the blow, to strike back, to attack it? Fear is a very powerful mechanism that should only be activated in dangerous situations. If we use fear for educational purposes we will project very deep blockages in the new generations. However, when we recognize and accompany the thoughts and impulses generated by fear, they become silent. Once silenced, they are no longer activated unconsciously. Therefore, if we look at what is happening, consciously, "without judgement" it will facilitate our journey towards our true SELF. The EmocionaTFamilia program invites us to accompany our path "lightly and at the right time". Change is simple, the lesson is the opposite of what we have learned.
\end{abstract}

Volume II Issue 6 - 202I

\author{
María del Carmen Díez González,' Rafael \\ Marcos Sánchez ${ }^{2}$ \\ 'Department of Education Sciences. CEU Cardenal Herrera \\ University, Spain \\ ${ }^{2}$ Department of Mathematics and Business Studies. International \\ University of La Rioja, Spain
}

\begin{abstract}
Correspondence: Maria Carmen, C/Andrés Torrejón N/9, 6Dcha, Elche 03202 (Alicante). Spain, Tel 0034 677170502, Email maria_carmen.diez@uchceu.es
\end{abstract}

Received: November 22, 2021 | Published: December 13, 2021

Keywords: fear, unconsciousness, path, emotion and family

\section{Introduction}

Emotions play a fundamental role since childhood as they have an adaptive and connecting function with our organism. This connection extends and increases as they become present. All emotions have something in common, "their dementia" as they are composed of images that cannot be seen and sounds that cannot be heard. For they only make sense to their maker, since only he perceives them. The repression of emotion prevents natural movement and leads to a stagnation of the organic systems that feed on it.

Psychologically speaking, emotions alter perception, attention, condition our behaviors and activate memory. When emotions cause disorder, learned and repeated experience reduces the positive emotional charge, leading to dysfunction in the mind-body system. Much research has been done on parent-child relationships, on the level of general intelligence. However, in the emotional sphere it has been studied more recently. Emotional accompaniment invites us to make a journey on the why and how these experiences are channeled through education. ${ }^{1,2}$

The fear of life is really the fear of emotions. In fact, we are more afraid of the feelings associated with the facts than of the facts themselves. Should we therefore learn from each fact in order to be able to face it, or do we choose to shut ourselves up in the situation for fear of growing? Do we choose hope or discouragement, do we choose to shut ourselves up in bitterness or do we mentally attack what bothers us? Every emotional experience is an opportunity to grow. Therefore, what do we choose? That is the dilemma.

This accompaniment is immersed in the program EmocionaTFamilia: Social-emotional health, aimed at the family coexistence of children, adolescents and their families. The program is based on an inner journey that travels from attentive serenity, conscious emotional strengths and lands in conversations around the table. The EmocionaTFamilia program helps us to preserve physical and mental health by addressing both internal demands (such as feeding emotions) and external demands (such as interpersonal relationships). Learned helplessness, exaggerations, discouraging beliefs, fears, defeatist discourses that can be replaced, through a process of "mental hygiene", by feelings of calm, confidence, security, and psychological strength. ${ }^{3}$ We are going to observe, as if we were looking at them with a magnifying glass, the different faces of fear.

The faces of fear bring us closer to the past or to the future and all of them show different levels of graduation. The softer faces of fear make us uneasy and uncomfortable; while the more abrupt faces of fear paralyze us, disconcert us and make us feel trapped, guilty, submissive, etc., with a clear absence of love. Certainly, these words may resonate with us and even surprise us, for fear has so many faces that we could not possibly summarize them in these lines. When fear arises from the most unconscious stage of the brain it is appropriate to look at the other apices of its recipe. So, what are the ingredients of fear?

\section{Material and methods}

Seventy participants took part in the present study. The participants have degrees related to the department of Education and Health. The research and fear detection study was conducted during the months of March-September 2021 (in the PostCOVID era). In the study teachers were asked three questions, firstly, choose one type of fear and mention it; secondly, what fuels your fear? And thirdly, consequences of fear. The participants filled in their data sheet with the answers to the questions posed, and these answers were categorized according to the typology of the environment and the evolutionary age that corresponds to the fear. Based on these answers, they were offered a session of observation of the fears raised.

\section{Results}

As we can see, the data show two faces of fear, which we will explain in more detail below in Table 1. In Table 1, we can observe the classification analysed according to the typology of the fear, the explanation of the travellers' fears and the consequences in their lives. In addition, we have added the evolutionary age from which their fears arise since they have been reactivated in adulthood. This classification is divided into two types of fears, existential fears that can be real and/ or not real and projective fears that are not real. Next, we are going to detail the fears of the travellers in the program. 
Table I Results of the fears reflected in the sample analysed

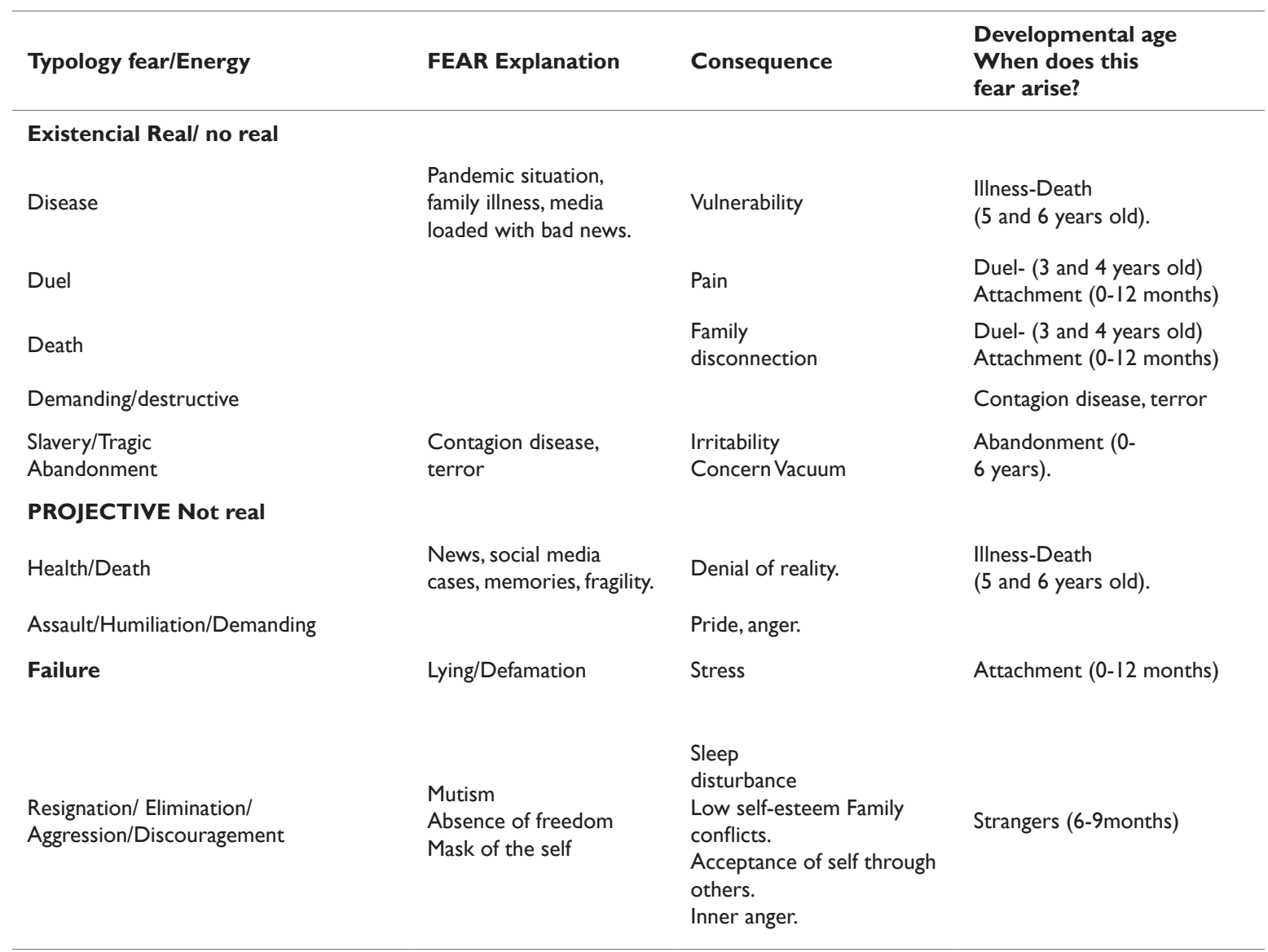

Source: EmocionaTFamilia

Based on the detection and results found with the post-COVID study, we set out on the journey with the EmocionaTFamilia Program. To channel our BEING we entered EmocionaTFamilia where seven sessions are developed that nourish the three pillars of the program. The pillar of Full Attention (PA), the pillar of the Observatory of Emotional Strengths (OFE) and the pillar of the Practice-Conversations-Table (PCM). For more information (Table 2).

Table 2 Sessions of the EmocionaTFamilia Program

\begin{tabular}{lll}
\hline Full Attention (PA) & Schedule & September \\
Observatory - Emotional & 2. RECONOCET-AP & October \\
Strengths (OFE) & 3.PERCIBET-AP & November \\
4. EXCITED -OFE & January
\end{tabular}


Table Continued..

\begin{tabular}{lll}
\hline SESSIONS & Schedule \\
$\begin{array}{l}\text { Practice - Conversation - } \\
\text { Table (PCM) }\end{array}$ & February & March \\
6.ACOMPANAT-PCM & April
\end{tabular}

Source: Programme aimed at students. Emociona Familia Team

\section{Discussion}

When we talk about existential fears, we are referring to fears related to one's own existence. These fears include the fear of death of one's own person, the fear of death of family members, the fear of abandonment or the fear of not being loved. All these fears are situated between real and/or not real for the person, since they can be the object of their imagination. Being the not real fears very constant in their mind. As if these fears were predicting the end, as if they were announcing this fact without being supported by the reason for the fact, denoting guilt, apathy and suffering. This type of fear disconnects us from the family, as our travellers reflect, as they lead us to emptiness and abandonment. From Evolutionary Psychology we observe how these fears have an origin in a very early stage of development, where each stage is prepared to understand fear in its kindest face and to be able to face it in its most abrupt faces. ${ }^{2,4}$ As we can observe, the travellers in the programme reflect a return to the more abrupt face of fear. The pandemic has reactivated in their minds the mourning, disease, death, carrying such fears a great burden of demand, destruction, slavery, tragedy and a clear deep sense of abandonment. ${ }^{5}$ Whose consequences have left them with ingredients that do not fit the original recipe, vulnerability, pain, family disconnection, irritability, restlessness and emptiness.

On the other hand, we stop to observe the projective fears that adults feel and place in their children and/or students, making them participants in them, without being fully aware of them. These fears are situated in the fragility of the person, in the denial of reality, they denote anger and pride, stress, sleep disturbances, family conflicts, difficulties in accepting the "I" and a clear inner anger. As we can observe, the travellers in the programme again reflect the more abrupt face of fear projected in the possession of the other self. This possession denotes a clear absence of accompanying attachment and fear of what they cannot control, i.e., the stranger. As you can see in table 1, these are developmental fears that arise from 0 to 12 months and can lead to nightmares, loneliness, sleep disturbances, anxiety, among other indicators. It is like having the sensation of disappearing or of being devoured if we do not possess the other, certainly it can be astonishing and even painful. All this shows us the way to create it again, in a lighter way, more understanding and with more serenity.

\section{Conclusion}

Human beings need to establish affective bonds with other people, that is where learning begins, with physical presence. ${ }^{6}$ Parents and family are the first educational and socializing agents of children.
Children from an early age imitate the behaviors they observe in their parents. ${ }^{7}$ The imitation of these behaviors can be the cause and also the consequence of the problems that children develop. Families have to transfer an adequate emotional accompaniment supported with the right ingredients so that the recipe is original. For this reason, Emotional Accompaniment begins at home and even more so in these times of change in the face of the pandemic. Children mature emotionally as adults teach them and practice with them. ${ }^{5}$

In many occasions the intense social and intellectual development can eclipse the affective phenomena. It is even observed how the "fears" of children and/or adults increase in proportion to the severity and complexity of the world. Now, each bond that we initiate from our childhood stage, adds more "apices" to our character, ways of seeing life, attitudes, among others; hence the importance of the first years of life and how relationships and education are Fenty et al. ${ }^{8}$ The emotional blocks of fear are implicit in our unconscious called by Carl Jung as "the shadow". These shadows become very black, like the color that does not let the light through, that does not allow us to see what is behind, that you do not know what it hides and leaves you in solitude.

Therefore, an adequate quality Education requires that the academic authorities provide subjects and time "without a clock" for Emotional Accompaniment. So that the new generations are nourished with serenity, with joy that leads them to become aware in making decisions as "future professionals" and above all as "people in peace".

\section{Acknowledgments}

Thanks to all the teachers who have shared their fears with the studio.

\section{Conflicts of interest}

The authors declare no conflicts of interest.

\section{References}

1. Lopez González L. Correlational study between relaxation, classroom climate. 2004.

2. Mujica FN, Orellana MC. Emotions of Chilean physical education teachers in the context of pandemic. Challenges: new trends in physical education, sport and recreation. 2022;43:861-867.

3. Justicia-Arráez A, Pichardo C, Justicia F. Effect of the Learning to Live Together program on social competence and behavioral problems in 3-year-old students. Electronic Journal of Research in Educational Psychology. 2015;11(3):825-836. 
4. Toro JM. Educating with “co-reason”. Bilbao: Desclee De Brouwer. 2012.

5. Hernández G. Emotion management in times of pandemic and its impact on academic performance. Journal of research and culture. $2020 ;(9) 4: 44-64$.

6. Yager JM, Fisher SW, Shearon DN. SMART Strengths. Building Character, Resilience and Relationships in Youth. New York: Kravis Publishing. 2011
7. Collado D, Cadenas C. Emotion education, a challenge? E-motion. Journal of Education, Motricity and Research, 1, 196-211.

8. Fenty NS, Miller MA, Lampi A. Embed social skills instruction in inclusive settings. Intervention in school and clinic. 2013;43(3):186-192. 